\title{
Optimum spectral window for imaging of art with optical coherence tomography
}

\author{
Haida Liang, ${ }^{1, *}$ Rebecca Lange, ${ }^{1}$ Borislava Peric, ${ }^{1}$ \\ and Marika Spring ${ }^{2}$ \\ ${ }^{1}$ School of Science and Technology, Nottingham Trent University, Nottingham NG11 8NS, UK \\ ${ }^{2}$ ScienificDepartment, The National Gallery, London WC2N 5DN, UK \\ *Haida.Liang@ntu.ac.uk
}

\begin{abstract}
Optical Coherence Tomography (OCT) has been shown to have potential for important applications in the field of art conservation and archaeology due to its ability to image subsurface microstructures noninvasively. However, its depth of penetration in painted objects is limited due to the strong scattering properties of artists' paints. VIS-NIR (400 nm $2400 \mathrm{~nm}$ ) reflectance spectra of a wide variety of paints made with historic artists' pigments have been measured. The best spectral window with which to use optical coherence tomography (OCT) for the imaging of subsurface structure of paintings was found to be around $2.2 \mu \mathrm{m}$. The same spectral window would also be most suitable for direct infrared imaging of preparatory sketches under the paint layers. The reflectance spectra from a large sample of chemically verified pigments provide information on the spectral transparency of historic artists' pigments/paints as well as a reference set of spectra for pigment identification. The results of the paper suggest that broadband sources at $\sim 2$ microns are highly desirable for OCT applications in art and potentially material science in general.
\end{abstract}

The final publication is available at Springer via http://dx.doi.org/10.1007/s00340-0135378-5 Applied Physics B (2013) 111:589-602

\section{Introduction}

Optical coherence tomography (OCT) is a fast non-invasive imaging technology based on a Michelson interferometer using broadband laser sources; it is capable of non-contact imaging of the 3D subsurface internal microstructure of transparent or semi-transparent material [1][2]. It is usually used for biomedical applications such as in vivo imaging of the interiors of the eye, skin and other biological tissues. In the last 10 years, OCT has found increasing applications for non-biological materials [3]. In particular, it offers the possibility of noninvasive and non-contact examination of the subsurface microstructure of historic paintings (Fig. 1c), including paint and varnish layers [4][5][6][7][8][9], as well as other historic objects [10][11]. Currently, the routine method of investigating the stratigraphy is through taking a small sample from a painting, 300-500 $\mu \mathrm{m}$ in size, and preparing it as a cross-section that can be examined under a microscope (Fig. 1b). OCT imaging allows any area of the painting to be probed, rather than being restricted to a handful of tiny paint samples. It is particularly effective when used in conjunction with traditional methods, reducing the need for sampling and giving a more representative view of a painting as a whole [6][8]. Figure 1 shows a comparison of a microscope image of a paint cross-section with an OCT image from a similar region. The shadow of an underdrawing can be seen in the OCT image taken in cross-section (Fig. 1c), showing that it is located $\sim 100 \mu \mathrm{m}$ in optical depth below the painting surface. Assuming that the varnish and paint layers have refractive indices of $\sim 1.45$, the varnish and 
paint layers above the underdrawing would be about $70 \mu \mathrm{m}$ thick in total, consistent with the paint and varnish thickness in the paint cross-section (Fig. 1b).

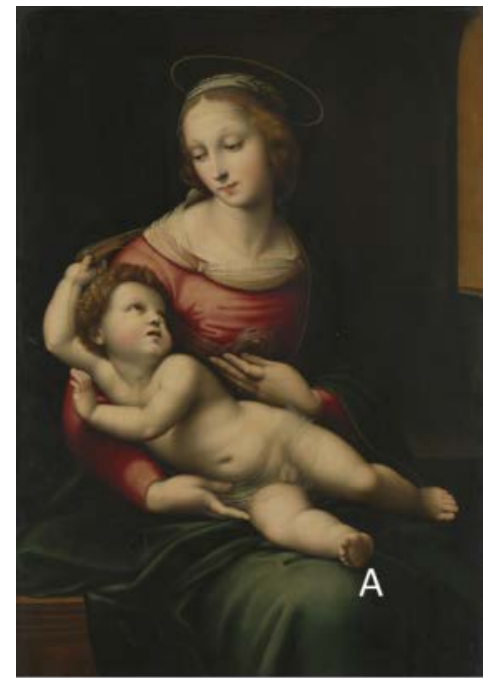

(a)

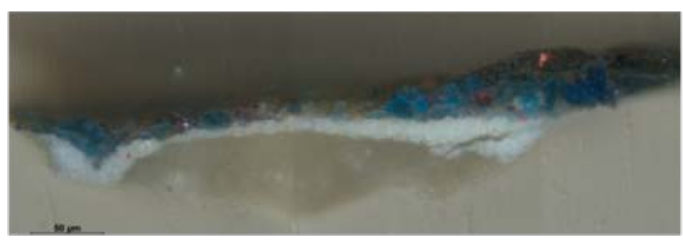

(b)

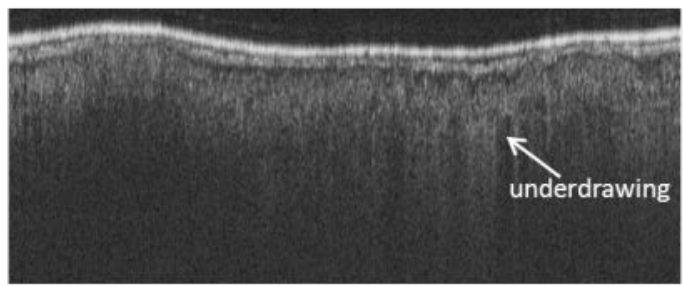

(c)

Fig. 1 After Raphael, The Madonna and Child (NG929), probably before 1600 (c) National Gallery London: a) colour image of the painting; b) an image of a small paint cross-section sample (taken from the Virgin's blue cloak which appears green because of the yellowed varnish) under the microscope (460 $\mu \mathrm{m}$ wide, aspect ratio 1:1) showing from the top downwards several varnish layers and possibly overpaint, blue paint containing azurite and a little red lake, a white priming layer and a ground layer containing chalk (appears translucent and greyish in the sample); c) OCT image in cross-section (8mm wide and 0.4mm in depth) of the region marked 'A' in a) in an area of the blue cloak showing layers of varnish and paint as well as columns of shadow cast by underdrawing.

For OCT in biomedical applications, various papers have been published on the determination of optimum wavelength for imaging of tissues to achieve the best penetration depth and resolution [12][13]. The optimum wavelength for high depth resolution and least extinction due to absorption is defined by the optical properties of water, since it is one of the main constituents of biological tissue. Water absorption peaks around 1.4-1.5 $\mu \mathrm{m}$ and 1.9-2.2 $\mu \mathrm{m}$; scattering decreases for biological tissues with increasing wavelength [13]. Optical dispersion is another concern since it degrades the depth resolution for thick layers of biological tissue $(>1 \mathrm{~mm})$ in ultra-high resolution OCT.

Material encountered in cultural heritage is by nature extremely heterogeneous. Figure 2 shows OCT cross-section images at 930nm of four paint samples with a range of optical properties. Most paints are highly scattering and the occurrence of multiple scattering is common. The bright pixels below the paint/glass interface in Fig. $2 \mathrm{~b}$ are due to multiple scattering. In contrast with biological tissues, water is not a dominating concern for OCT imaging of paint materials. Increasing the penetration depth is even more crucial to OCT imaging of paint layers than biological tissues, since most paints are more strongly scattering than common biological tissues such as skin. In the paintings field, studies have been made to investigate the optimum spectral window for infrared imaging of preparatory sketches or underdrawings beneath paint layers. It was known already in the 1930s that paint is more transparent in the near infrared than the visible spectral range. Until the late 1960s, infrared photography of old master paintings was used to reveal underdrawings, changes made by the artist and areas of paint loss or retouching. With this technique, underdrawing could not be 
seen beneath paint containing certain common pigments such as azurite and malachite since the film was sensitive in the 700-900 nm region but the pigments show absorption in this wavelength range. In 1968, a vidicon-based near infrared imaging device was invented which allowed imaging in the wavelength range $900 \mathrm{~nm}$ to $2 \mu \mathrm{m}$ [14]. Studies on the spectral transparency in the near infrared up to $2.5 \mu \mathrm{m}$ of a handful of oil paints have been conducted through measuring the spectral transmittance and deriving the hiding thickness [15]. In another study, the best instrument for imaging underdrawings was qualitatively determined by using cameras with different spectral sensitivities (a Hamamatsu lead sulphide vidicon camera and a Photometrics silicon CCD) and broad band near infrared filters $(750 \mathrm{~nm}, 800 \mathrm{~nm}, 900 \mathrm{~nm}$ and $1000 \mathrm{~nm}$ ) to image test panels of oil paints (based on 24 pigments) painted over a set of 7 common underdrawing materials [16]. A more recent study was conducted on 17 pigments (14 in oil binding medium and 3 in egg tempera binding medium) through both measuring the spectral transmittance $(400-2500 \mathrm{~nm})$ and comparing contrasts of mock underdrawings under different paints using cameras of different spectral sensitivities [17]. A recent qualitative study was conducted on 47 commercial oil paints at $823 \mathrm{~nm}$ and $1550 \mathrm{~nm}$ using available OCT instruments [18]. Unfortunately, these OCT systems did not happen to have the same resolution and sensitivity.

There has not, however, been a quantitative study of the spectral transparency of a wide range of paint reference samples prepared with pigments with verified chemical compositions; the pigment name given by a supplier does not always accurately reflect the composition, or other materials might be present that affect the optical properties, such as fillers and extenders or impurities in natural pigments. In addition, all the studies so far have concentrated on oil paints. This paper presents a comprehensive study of the spectral transparency in the visible and the near infrared $(400 \mathrm{~nm}-2400 \mathrm{~nm})$ of paint made from 45 pigments found in historic European paintings in two common binding media (linseed oil and egg tempera).

Two main approaches have generally been taken in determining the optimum spectral window for OCT imaging of biological tissues: quantitative spectroscopic measurements of tissue optical properties to determine the optimum spectral window [12][13], and direct comparison using OCT at a number of common spectral windows defined by the availability of sources [19][20][21]. The disadvantage of the latter approach is that the comparisons tend to be qualitative as different OCT instruments have different inherent sensitivities and resolutions [22][23]. Recent studies have attempted to compare images from OCT systems that have been adapted so that they have similar instrumental parameters, which required separate purposebuilt instruments for each wavelength that was investigated [20][21], a very time consuming and costly approach.

In the present study, we measured the spectral transparency of each pigment in either an oil or egg tempera binding medium directly using diffuse reflectance spectroscopy over a white or black background and qualitatively correlated the results with OCT images of the same reference samples at two wavelengths $(930 \mathrm{~nm}$ and $1300 \mathrm{~nm})$. The 930nm OCT is a Thorlabs SROCT (spectral domain OCT) with a depth resolution of $\sim 7 \mu \mathrm{m}$ and transverse resolution of $\sim 9 \mu \mathrm{m}$; the 1310nm OCT is a Zeiss Visante time domain system with a depth resolution of $\sim 18 \mu \mathrm{m}$ and transverse resolution of $\sim 20 \mu \mathrm{m}$.

The set of spectral reflectance curves of chemically well-characterized paint references produced during this study will be made available online as they are also useful more generally for other applications such as non-invasive pigment identification based on reflectance spectra. 


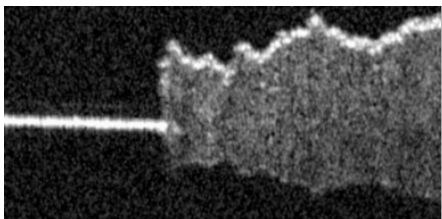

(a)

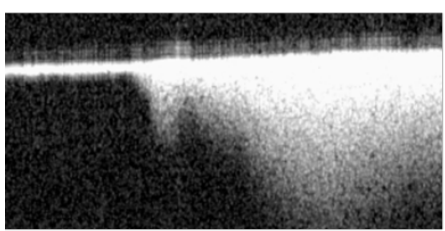

(c)

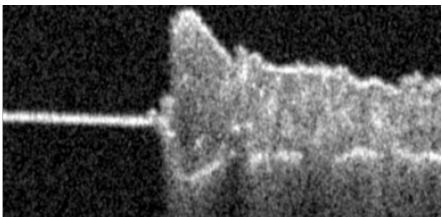

(b)

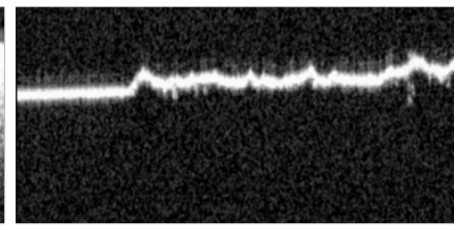

(d)

Fig. 2 Examples of OCT (930nm) cross-section images of paint reference samples (paint layer over a glass substrate) dominated by a) single scattering (oil paint of madder lake, fifteenth-century type); b) some multiple scattering (madder lake, nineteenth-century type in egg tempera); c) strong multiple scattering (Titanium white in linseed oil) and d) strong absorption (charcoal black in linseed oil). Details of the reference samples can be found in Table 1 and section 2.1. The left hand side of the images are regions with bare glass substrate. The images are all $3 \mathrm{~mm}$ wide and $0.46 \mathrm{~mm}$ in depth.

\section{Reference paint samples}

\subsection{Sample selection}

A set of paint reference samples were prepared consisting of 45 pigments chosen to be representative of those found on historic paintings (listed in Table 1), bound in either egg tempera (egg yolk) or oil (Winsor and Newton drying linseed oil, containing manganese as the siccative).The pigments were all examined under the optical microscope and with energy dispersive X-ray analysis in the scanning electron microscope to verify their composition and to identify any additives, fillers or extenders that might be present. In some cases further analysis was carried out with Fourier transform infrared microscopy, X-ray diffraction and/or Raman microscopy. Most of the pigments were supplied by either Kremer Pigmente or L. Cornelissen \& Son, with a few from The Pigment Factory Beijing. Natural pigments in particular can be variable in their composition, containing accessory minerals that could influence their absorption properties in the infrared. The highest quality natural ultramarine available from Kremer Pigmente (source unknown), for example, was found to be abnormally rich in pyrite (iron sulphide) impurities, making the pigment less transparent in the infrared than it is known to be from experience of infrared imaging of old master paintings. Natural ultramarine from Cornelissen was chosen instead, since it contains far less pyrite and has more typical properties, even though it is made from mineral from Chile rather than from the historic deposits in Afghanistan and does therefore differ slightly in the proportions of the various colourless minerals associated with the blue lazurite. The red and yellow lake pigments (with the exception of rose madder) had been prepared in the National Gallery laboratory during previous projects using a range of different recipes. They were made from various different dyestuffs, either extracted directly from the raw material or from dyed textile shearings which were often used as a source in the past. The dyestuff was extracted into solution and then precipitated onto a white substrate which was generally amorphous hydrated alumina (with some variation depending on the recipe, see Table 1), sometimes with the addition of chalk. The yellow lakes contain rather less alumina and are rich in chalk, as they 
usually are in historic paintings, making them slightly more opaque than lake pigments based on alumina. The recipes for all except the lac lake pigment can be found at www.organiccolorants.org, as can HPLC (High-performance liquid chromatography) analyses of the dyestuff components. The Lac lake was also made using a traditional recipe, one which results in the dyestuff being precipitated on an alumina substrate. Some of the pigments were available in different particle sizes. Three grades of malachite and azurite, and two grades of smalt were used to make reference paints to investigate the effect of this property on the reflectance spectra and transparency. This also reflects historic practice, since artists are known to have used different grades of these pigments, which would have had slightly differing colours.

\subsection{Sample preparation}

The paints were prepared by gradually adding binding medium to the pigment powder until the mixture reached a suitable consistency. They were then hand ground with a glass muller for up to fifteen minutes to ensure a homogeneous mixture. The amount of binding medium necessary to make paint with satisfactory handling properties varies significantly between different types of pigment due to varying oil adsorption properties and particle sizes. It was important not to add too much medium, which would give a runny rather than pasty paint, or too little, since the paint would be under-bound and in extreme cases powdery. The pigment volume concentration (PVC), defined as the volume of pigment relative to the total volume of dry paint, has an important influence on both the optical and physical properties of the paint film. At the critical pigment volume concentration (CPVC) there is just enough binding medium to fill the spaces between the pigment particles. Any less would result in voids in the paint film. The CPVC depends on the particle size and also on the interaction of the pigment surface with the binder. Pigments such as smalt, azurite and malachite are usually of relatively large particle size and need a higher proportion of medium to achieve CPVC, while paint containing red lake is also usually medium rich due to its adsorption properties rather than particle size. No attempt was made to achieve consistency in PVC between the paints, as the aim was to achieve a workable paint film. The mass of pigment and medium that was used was however recorded, and even though this does not determine the PVC directly, qualitative judgements can at least be made as to whether the film is likely to be medium rich or lean. For natural malachite and azurite (both Grade 1) a set of paints were also made which had four different proportions of pigment to medium (egg tempera) to investigate the influence of PVC on the optical properties.

The paints were applied on glass microscope slides using shims to give films of various wet thicknesses from $<50 \mu \mathrm{m}$ to $200 \mu \mathrm{m}$. While it was possible to control the wet thickness of the film, it was impossible to control the dry thickness. The thinnest paints were used to measure the spectral variations in transparency. These generally had a dry thickness of between $\sim 20$ to $50 \mu \mathrm{m}$. It would have been desirable for this study to create a set of reference paints which had uniform particle size, thickness and pigment volume concentration so that the effect of these factors on the spectra could be excluded. However, as well as not being possible for the practical reasons discussed above relating to the inherent properties of the different pigments, it would not reflect what is actually found in old master paintings.

The same paints were also applied on small white boards with commercially prepared gesso grounds onto which lines had been drawn in different materials (Fig. 12a). These were used as references for the investigation of the optimum spectral window for imaging of underdrawings. 
Table 1. Pigments used to prepare the reference paints and the major components as determined by analysis

\begin{tabular}{|c|c|}
\hline Pigment name and supplier & Composition (major components) \\
\hline \multicolumn{2}{|l|}{ BLUE } \\
\hline $\begin{array}{l}\text { Azurite (Grade 1, 3, 5; average particle sizes } \\
30 \mu \mathrm{m}, 5 \mu \mathrm{m}, 3 \mu \mathrm{m}) \text { : The Pigment Factory } \\
\text { Beijing }\end{array}$ & $\begin{array}{l}\text { Azurite, } 2 \mathrm{CuCO}_{3} \cdot \mathrm{Cu}(\mathrm{OH})_{2} \text {, with small amounts of } \\
\text { silicaceous minerals (EDX) }\end{array}$ \\
\hline Azurite MP (extra deep): Kremer Pigmente & $\begin{array}{l}\text { Azurite, 2CuCO3.Cu(OH)2, with small amounts of } \\
\text { silicaceous minerals (EDX) }\end{array}$ \\
\hline Cobalt blue medium: Kremer Pigmente & Cobalt aluminium oxide, $\mathrm{CoO} . \mathrm{Al}_{2} \mathrm{O}_{3}(\mathrm{EDX})$ \\
\hline Cerulean blue: Kremer Pigmente & $\begin{array}{l}\text { Cobalt stannate with excess tin oxide, a little barium } \\
\text { sulphate, some magnesium oxide (EDX) }\end{array}$ \\
\hline Indigo, genuine: Kremer Pigmente & Indigo and silicaceous extender (EDX, FTIR) \\
\hline $\begin{array}{l}\text { Lapis Lazuli deep (Chilean origin): L. } \\
\text { Cornelissen \& Son }\end{array}$ & $\begin{array}{l}\text { Mainly blue lazurite (sulphur-containing sodium } \\
\text { aluminosilicate), with colourless wollastonite } \\
\left(\mathrm{CaSiO}_{3}\right) \text {, a little red iron oxide (EDX, FTIR) }\end{array}$ \\
\hline Manganese blue: Kremer Pigmente & Barium manganate sulphate \\
\hline Prussian blue (Milori Blue): Kremer Pigmente & $\begin{array}{l}\text { Hydrated iron hexacyanoferrate complex, } \\
\mathrm{KFe}\left[\mathrm{Fe}(\mathrm{CN})_{6}\right] \cdot \mathrm{H}_{2} \mathrm{O}(\mathrm{EDX})\end{array}$ \\
\hline $\begin{array}{l}\text { Smalt (dark, } 200 \text { mesh, } 74 \mu \mathrm{m} \text {; light, } 400 \\
\text { mesh, } 37 \mu \mathrm{m}): \text { L. Cornelissen \& Son }\end{array}$ & $\begin{array}{l}\text { Cobalt-containing potash glass (Si, K, Co only: EDX, } \\
\text { FTIR) }\end{array}$ \\
\hline $\begin{array}{l}\text { Ultramarine blue, synthetic (dark, light): } \\
\text { Kremer Pigmente }\end{array}$ & $\begin{array}{l}\text { Sulphur-containing sodium aluminosilicate, approx. } \\
\mathrm{Na}_{6-10} \mathrm{Al}_{6} \mathrm{Si}_{6} \mathrm{O}_{24} \mathrm{~S}_{2-4} \text {, another aluminosilicate which is } \\
\text { probably kaolinite. Ultramarine blue light contains } \\
\text { some calcium carbonate in addition (EDX, FTIR) }\end{array}$ \\
\hline \multicolumn{2}{|r|}{ 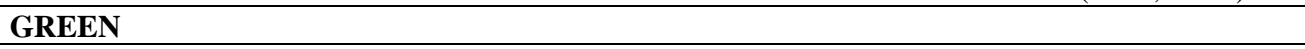 } \\
\hline $\begin{array}{l}\text { Natural malachite (Grades 1, 3, 5; average } \\
\text { particle sizes } 34 \mu \mathrm{m}, 9 \mu \mathrm{m}, 4 \mu \mathrm{m}) \text { : The Pigment } \\
\text { Factory Beijing }\end{array}$ & $\begin{array}{l}\text { Malachite, } \mathrm{CuCO}_{3} \cdot \mathrm{Cu}(\mathrm{OH})_{2} \text {, and a little copper } \\
\text { phosphate (FTIR, EDX) }\end{array}$ \\
\hline Bavarian green earth: Kremer Pigmente & $\begin{array}{l}\text { Mainly celadonite, } \mathrm{K}\left(\mathrm{Mg}, \mathrm{Fe}^{2+}\right) \mathrm{Fe}_{3+}\left(\mathrm{Si}_{4} \mathrm{O}_{10}\right)(\mathrm{OH})_{2} \text {, } \\
\text { according to supplier, with some quartz (EDX) }\end{array}$ \\
\hline Verdigris (synthetic): Kremer Pigmente & Copper acetate (EDX, FTIR) \\
\hline Viridian green: L. Cornelissen \& Son & Hydrated chromium oxide, $\mathrm{Cr}_{2} \mathrm{O}_{3} \cdot 2 \mathrm{H}_{2} \mathrm{O}$ (EDX) \\
\hline \multicolumn{2}{|l|}{ PURPLE } \\
\hline Cobalt violet (dark, light): Kremer Pigmente & Cobalt phosphate, $\mathrm{Co}_{3}\left(\mathrm{PO}_{4}\right)_{2}(\mathrm{EDX})$ \\
\hline Manganese violet: Kremer Pigmente & $\begin{array}{l}\text { Manganese ammonium pyrophosphate, } \mathrm{NH}_{4} \mathrm{MnP}_{2} \mathrm{O}_{7} \text {, } \\
\text { extended with potassium aluminium silicate (EDX) }\end{array}$ \\
\hline \multicolumn{2}{|r|}{ 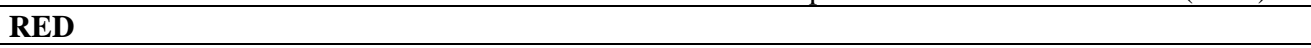 } \\
\hline Cadmium red: L. Cornelissen \& Son & Cadmium selenium sulphide, Cd(S,Se) (EDX) \\
\hline Chrome red: Kremer Pigmente & $\begin{array}{l}\text { Lead chromate, } \mathrm{PbCrO}_{4} \text {, significant amount of barium } \\
\text { sulphate (EDX) }\end{array}$ \\
\hline Cochineal lake: NG laboratory & $\begin{array}{l}\text { Mexican cochineal dyestuff on an alumina substrate } \\
\text { (HPLC, EDX, FTIR). Bolognese MS recipe (see } \\
\text { www.organiccolorants.org) }\end{array}$ \\
\hline French ochre (RTFLES): Kremer Pigmente & $\begin{array}{l}\text { Natural red earth from France. Iron oxide-containing } \\
\text { aluminosilicate. }\end{array}$ \\
\hline Lac lake: NG laboratory & Lac dyestuff on an alumina substrate (EDX) \\
\hline $\begin{array}{l}\text { Madder lake: NG laboratory, fifteenth-century } \\
\text { type }\end{array}$ & $\begin{array}{l}\text { Madder lake dyestuff extracted from dyed wool, } \\
\text { sulphur and wool protein incorporated into substrate, } \\
\text { together with some alumina. Recipe derived from } \\
\text { Nuremberg Kunstbuch, second half of } 15^{\text {th }} \text { century } \\
\text { (see madder recipe } 2 \text { in www.organiccolorants.org) }\end{array}$ \\
\hline $\begin{array}{l}\text { Madder lake: NG laboratory, nineteenth- } \\
\text { century type }\end{array}$ & $\begin{array}{l}\text { Madder dyestuff on a sulphate-containing alumina } \\
\text { substrate (EDX). Recipe from Riffault Deshêtres, }\end{array}$ \\
\hline
\end{tabular}




\begin{tabular}{|c|c|}
\hline & $\begin{array}{l}\text { Vergnaud and Toussaint, } 1884 \text { (see madder recipe } 1 \text { in } \\
\text { www.organiccolorants.org) }\end{array}$ \\
\hline Iron oxide red, natural: Kremer Pigmente & Natural red earth rich in iron oxide \\
\hline Red lead: Kremer Pigmente & Lead tetroxide, $\mathrm{Pb}_{3} \mathrm{O}_{4}(\mathrm{EDX})$ \\
\hline Rose madder (genuine): L. Cornelissen \& Son & $\begin{array}{l}\text { Madder dyestuff on a sulphate-containing alumina } \\
\text { substrate (nineteenth-century type red lake) (EDX) }\end{array}$ \\
\hline $\begin{array}{l}\text { Sappanwood lake (Brazilwood lake, redwood } \\
\text { lake): NG laboratory }\end{array}$ & $\begin{array}{l}\text { Sappanwood dyestuff on a sulphate-containing } \\
\text { alumina substrate (HPLC, EDX, FTIR). Bolognese MS } \\
\text { recipe (see www.organiccolorants.org) }\end{array}$ \\
\hline $\begin{array}{l}\text { Vermilion (Grade 3): The Pigment Factory } \\
\text { Beijing }\end{array}$ & Mercury sulphide, HgS (EDX) \\
\hline Vermilion light: Kremer Pigmente & Mercury sulphide, HgS (EDX) \\
\hline \multicolumn{2}{|l|}{ YELLOW } \\
\hline Cadmium yellow light: L. Cornelissen \& Son & $\begin{array}{l}\text { Cadmium sulphide (CdS) with a small amount of Zn, } \\
\text { some barium sulphate (EDX) }\end{array}$ \\
\hline Cadmium yellow deep: L. Cornelissen \& Son & $\begin{array}{l}\text { Cadmium sulphide with a little selenium, Cd(S,Se) } \\
\text { (consistent with orange colour), some barium sulphate } \\
\text { (EDX) }\end{array}$ \\
\hline Chrome yellow medium: Kremer Pigmente & Lead chromate, $\mathrm{PbCrO}_{4}(\mathrm{EDX})$ \\
\hline $\begin{array}{l}\text { Cobalt yellow (Aureolin): L. Cornelissen \& } \\
\text { Son }\end{array}$ & $\begin{array}{l}\text { Potassium cobaltinitrite, } \mathrm{K}_{3}\left[\mathrm{Co}\left(\mathrm{NO}_{2}\right)_{6}\right]+3 \mathrm{H}_{2} \mathrm{O} \text {, } \\
\text { according to supplier (EDX) }\end{array}$ \\
\hline $\begin{array}{l}\text { Dyer's broom lake (buckthorn lake): NG } \\
\text { laboratory }\end{array}$ & $\begin{array}{l}\text { Dyer's broom dyestuff on an alumina substrate with } \\
\text { chalk (HPLC, EDX, FTIR). Recipe derives from Boltz, } \\
1549 \text { (see recipe 1, www.organiccolorants.org) }\end{array}$ \\
\hline $\begin{array}{l}\text { Italian golden ochre, light yellow: Kremer } \\
\text { Pigmente }\end{array}$ & $\begin{array}{l}\text { Natural yellow earth. Iron oxide-containing } \\
\text { aluminosilicate, large proportion of calcium sulphate, } \\
\text { smaller amounts of calcium carbonate, dolomite, } \\
\text { magnesium-containing silicates, potassium aluminium } \\
\text { silicate, a little strontium sulphate (EDX) }\end{array}$ \\
\hline $\begin{array}{l}\text { Lead tin yellow, light (type I): Kremer } \\
\text { Pigmente }\end{array}$ & Lead stannate, $\mathrm{Pb}_{2} \mathrm{SnO}_{4}(\mathrm{EDX})$ \\
\hline $\begin{array}{l}\text { Lemon yellow, barium chromate: L. } \\
\text { Cornelissen \& Son }\end{array}$ & Barium chromate, $\mathrm{BaCrO}_{4}(\mathrm{EDX})$ \\
\hline Naples yellow light, genuine: Kremer Pigmente & $\begin{array}{l}\text { Lead antimonate, } \mathrm{Pb}_{2} \mathrm{Sb}_{2} \mathrm{O}_{7} \text {, with small amount of } \mathrm{Zn} \\
\text { and } \mathrm{Cl}(\mathrm{EDX})\end{array}$ \\
\hline $\begin{array}{l}\text { Terra di Sienna, Italian, Natural: Kremer } \\
\text { Pigmente }\end{array}$ & $\begin{array}{l}\text { Natural brownish-yellow earth. Iron oxide, } \\
\text { aluminosilicate of iron and magnesium, some of which } \\
\text { contains titanium in addition. }\end{array}$ \\
\hline $\begin{array}{l}\text { Realgar (Grade 3): The Pigment Factory } \\
\text { Beijing }\end{array}$ & $\begin{array}{l}\text { AsS, identified by XRD, also some calcium carbonate } \\
\text { (EDX) }\end{array}$ \\
\hline Orpiment : Kremer Pigmente & $\mathrm{As}_{2} \mathrm{~S}_{3}$ identified by XRD \\
\hline Weld lake: NG laboratory & $\begin{array}{l}\text { Weld dyestuff on an alumina substrate with chalk } \\
\text { (HPLC, EDX, FTIR). Recipe derives from Boltz, } 1549 \\
\text { (see Weld recipe 1, www.organiccolorants.org) }\end{array}$ \\
\hline \multicolumn{2}{|c|}{ WHITE } \\
\hline Lead white (Cremnitz white): Kremer Pigmente & Basic lead carbonate, $\mathrm{PbCO}_{3} \mathrm{~Pb}(\mathrm{OH})_{2}(\mathrm{EDX}, \mathrm{FTIR})$ \\
\hline Titanium white: L. Cornelissen \& Son & Titanium dioxide, $\mathrm{TiO}_{2}(\mathrm{EDX})$ \\
\hline Zinc white: L. Cornelissen \& Son & Zinc oxide, $\mathrm{ZnO}$ \\
\hline \multicolumn{2}{|l|}{ BLACK } \\
\hline Bone black: Kremer Pigmente & Calcium phosphate, $\mathrm{CaPO}_{4}$ (EDX, FTIR) \\
\hline Charcoal (from beech): Kremer Pigmente & \\
\hline
\end{tabular}




\section{Measurements of spectral reflectance and transparency}

The transparency of a paint layer depends on both the scattering and absorption properties, since light is both scattered and absorbed when it travels through the layer. For a strongly scattering paint layer, we expect the reflectance to be high and independent of whether the sample is placed on a white or black background. A highly absorbing paint layer would have low reflectance, independent of whether it is placed on a white or black background. In contrast, a highly transparent layer will have high reflectance when it is placed on a white background but low reflectance when placed over a black background. For paint layers, the depth of penetration achieved with OCT imaging is often limited by multiple scattering (e.g. Fig. 2c). A transmittance measurement through the sample alone is not sufficient in determining its transparency since forward scattering will also enhance the transmittance. A single transmittance measurement cannot distinguish between high transparency (i.e. low scattering and low absorption) and strong forward scattering. Since OCT works in a retroreflection configuration, measurement of reflectance in retro-reflection mode is more appropriate.

The degree of transparency $T$ is defined in this paper as:

$T(\lambda)=R_{w}(\lambda)-R_{B}(\lambda)$

where $R_{W}$ is the spectral reflectance of a paint sample when placed over a $99 \%$ reflecting diffuse white standard and $R_{B}$ is the spectral reflectance of a paint sample when placed over a 'black' background that reflects $<0.1 \%$ of the light (i.e. sample placed far away from any reflective background). The transparency thus defined gives the fraction of light that has penetrated through the paint layer and reflected back to the probe in retro-reflection with respect to that reflected from a $99 \%$ diffusely reflective white standard. This method gives spectrally continuous measurements of the relative transparency of each paint reference sample, which is better than direct measurements at discrete wavelengths using different OCT systems.

Since the samples do not have the same pigment-volume-concentration and dry thickness, the transparency thus determined only gives the relative spectral variation of transparency for each sample. These transparencies should not be compared between samples without taking into account the dry thickness and concentration of the paint at the position where the spectral reflectance was measured.

An Ocean Optics HR2000+ fibre optic spectrometer (200-1100nm), a Polychromix DTS 1700 $(900-1700 \mathrm{~nm})$ and DTS $2500(1700-2500 \mathrm{~nm})$ fibre optic spectrometer were used to measure the spectral reflectance between $400 \mathrm{~nm}$ and $2400 \mathrm{~nm}$. The spectral resolutions of the three spectrometers are $0.9 \mathrm{~nm}, 12 \mathrm{~nm}$ and $22 \mathrm{~nm}$. Figure 3 shows the experimental setup which was constructed so that a white standard could be placed under the sample, or removed, without changing the position of the measuring spot ( $5 \mathrm{~mm}$ in diameter). Glass is $>99 \%$ transparent over this wavelength range. The probe head was adjusted to an angle of 45 degrees to the normal above the sample to avoid specular reflection from the sample surface. It is the interaction of light with the paint material rather than the surface smoothness that is of interest in this study. A Tungsten light source was connected to the spectrometers through a fiber reflectance probe. The white reference was a Labsphere Spectralon 99\% diffuse reflection standard. Measurement of spectral reflectance of a sample over a black background was achieved by maintaining a large distance, $\sim 45 \mathrm{~cm}$, between the sample and the next possible reflecting surface (a piece of matt black paper). 


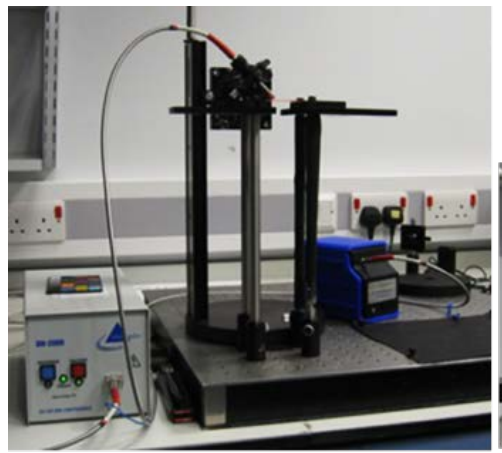

(a)

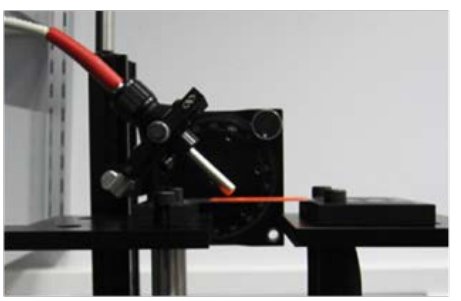

(b)

Fig. 3 Experimental setup for reflectance measurements: the sample is placed on a stage $\sim 45 \mathrm{~cm}$ from the optical table (covered in black) such that no light will be reflected back from the background into the fibre.

\section{Spectral transparency of historic artists' paint}

Figure 4a shows the spectral reflectance of a verdigris oil paint measured over a white and black background. The measured reflectance over a black background is nearly zero for the whole wavelength range. The reflectance spectrum over white shows a broad absorption feature between $600 \mathrm{~nm}$ and $1000 \mathrm{~nm}$ which is characteristic of copper based pigments. Based on the measurements, it is expected that the paint will be fairly transparent at $1310 \mathrm{~nm}$, but highly opaque due to absorption at $930 \mathrm{~nm}$, which is verified by OCT images at $930 \mathrm{~nm}$ and $1310 \mathrm{~nm}$. In the $930 \mathrm{~nm}$ image (Fig. 4c), only the top of the paint layer can be seen. In the 1310nm image (Fig. 4e), however, the entire thickness of the paint layer (showing moderate scattering but still dominated by single scattering) and the bottom of the glass microscope slide can be seen. Similarly, Fig. 4b shows the spectral reflectance of a cobalt blue paint over a white and black background. The spectra show broad absorption feature around 1300$1550 \mathrm{~nm}$ which is characteristic of cobalt based pigments. Around 930nm, the reflectance over white and over black are both moderately low indicating that the paint is in the regime where it is both moderately scattering and absorbing. The OCT images at 930 and 1310nm corroborate with the spectral measurements. Figure $4 \mathrm{~d}$ shows that at $930 \mathrm{~nm}$ the paint scatters significantly (multiple scattering dominates) and the extinction due to scattering and absorption is strong enough to mask the bottom of the glass microscope slide; Fig. 4f shows that at $1300 \mathrm{~nm}$ absorption by the paint dominates and only the top surface of the paint can be seen. 


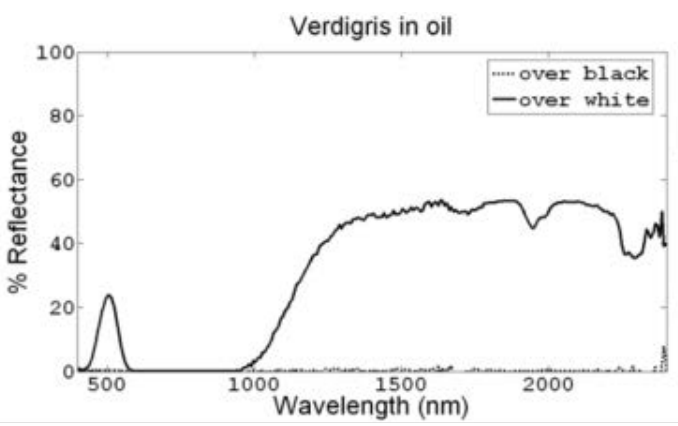

(a)

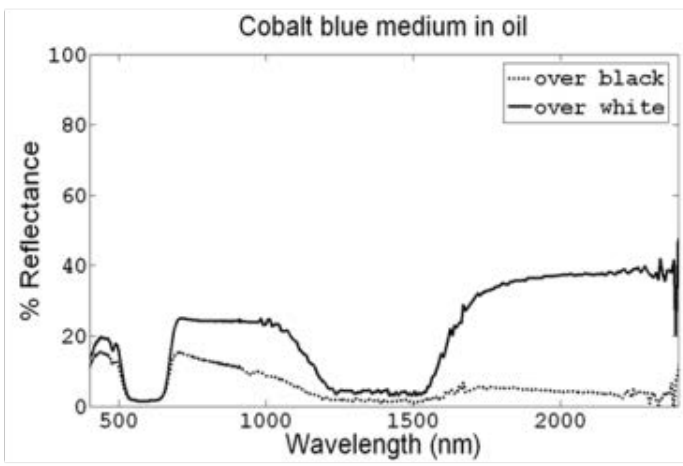

(b)

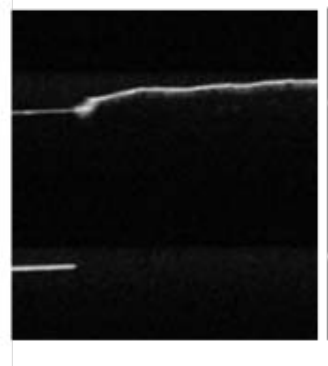

(c)

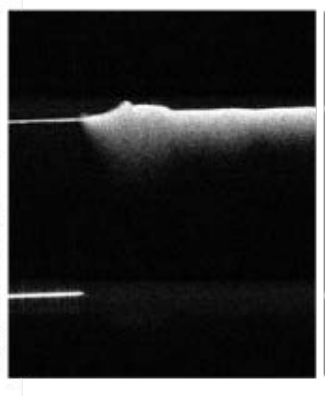

(d)

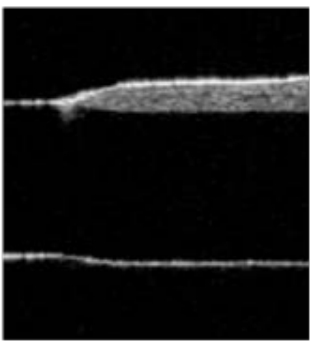

(e)

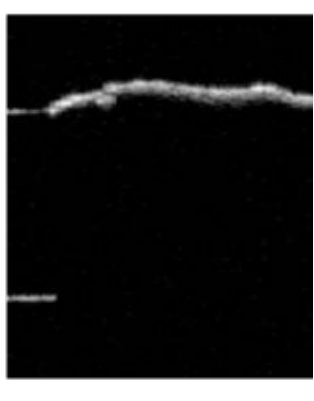

(f)

Fig. 4 a-b) Spectral reflectance of a sample of verdigris and cobalt blue oil paint measured over a white background (solid line) and measured over a black background (dotted line); OCT images in cross-section of the paints on a glass substrate at $930 \mathrm{~nm}(\mathrm{c}, \mathrm{d})$ and $1300 \mathrm{~nm}(\mathrm{e}, \mathrm{f})$. The left side of the OCT images is the bare glass substrate.

Figure 5 shows the normalized transparency (normalized to 1 at 2200nm) of the oil paints for each type of pigment. The spectrometers have different sensitivities with the HR2000+ having the best sensitivity and the DTS1700 having the worst sensitivity. All spectrometers have reduced sensitivity towards the edge of their operational range. For clarity, data in these regions have been removed leaving gaps in the data which also serves to distinguish data collected from different spectrometers. The normalization process significantly amplifies the noise for paints with low measured transparency which explains the difference in noise levels between some of the paint samples. Apart from the cobalt paints which have a minimum transparency between 1300-1600nm due to a broad absorption feature in their spectra, the transparency of all other paints increase with wavelength in the range of 1000-2200nm. This is consistent with what is known qualitatively. For the majority of paints, the maximum transparency occurs around $2.2 \mu \mathrm{m}$ over the entire wavelength range of $400-2400 \mathrm{~nm}$. Similar results are obtained with the egg tempera based pigments. 


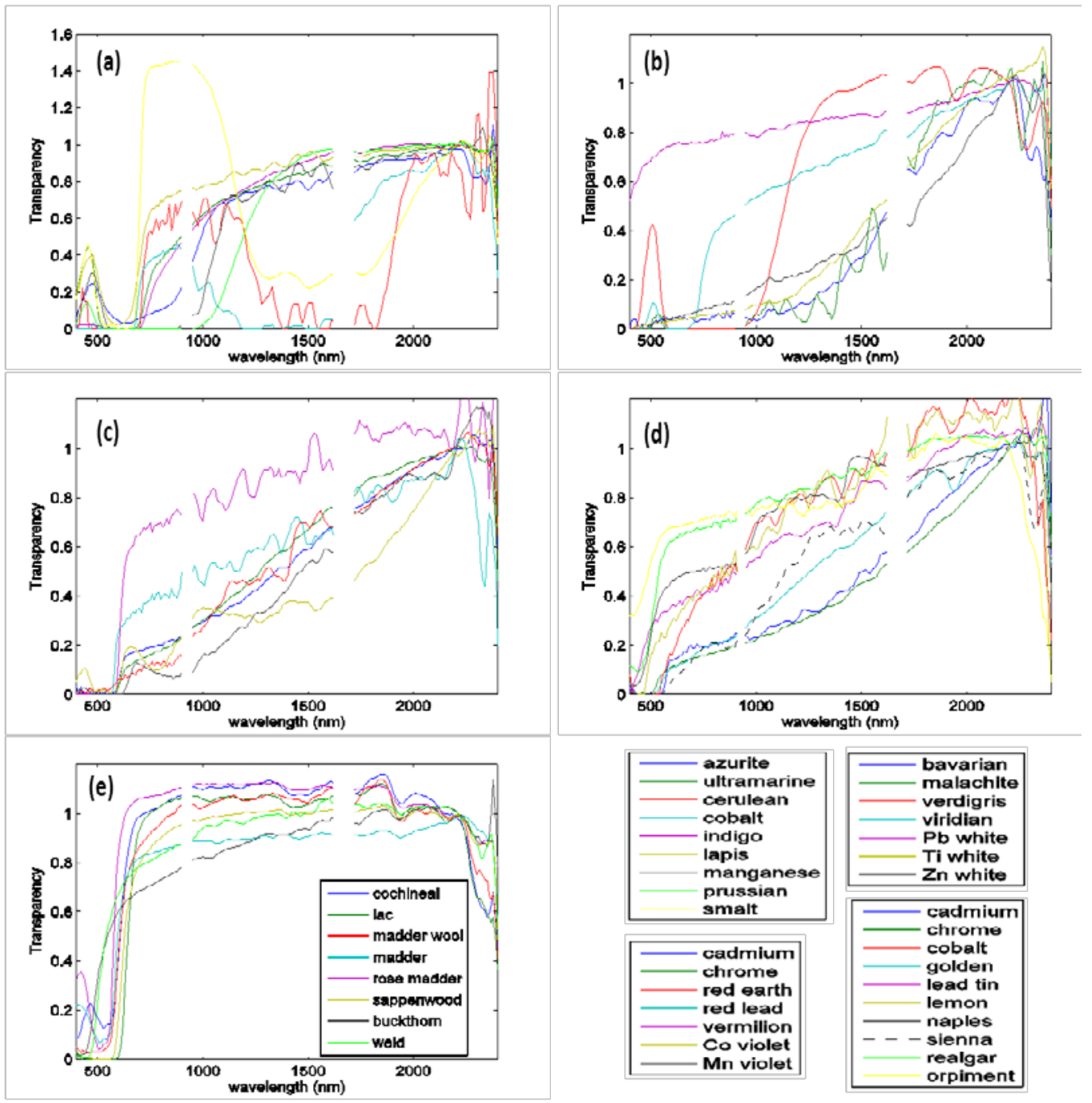

Fig. 5 Spectral transparency (normalized to 1 at 2200nm) for each type of pigments in oil: a) blue pigments; b) green and white pigments; c) red and purple pigments; d) yellow pigments and e) lake pigments. The legends for a) to d) are shown in the bottom right corner in their corresponding positions. The gaps are regions of low detector sensitivity at the edges of operation ranges for the 3 spectrometers.

Figure 6 shows the median normalized spectral transparency of 15 paints made from pigments in use before the nineteenth century (excluding lake pigments) in both oil and egg tempera. On average the transparency can also be seen to increase with increasing wavelength, and the conclusions on the optimum spectral window for maximum transparency is the same as the full data set discussed above. 


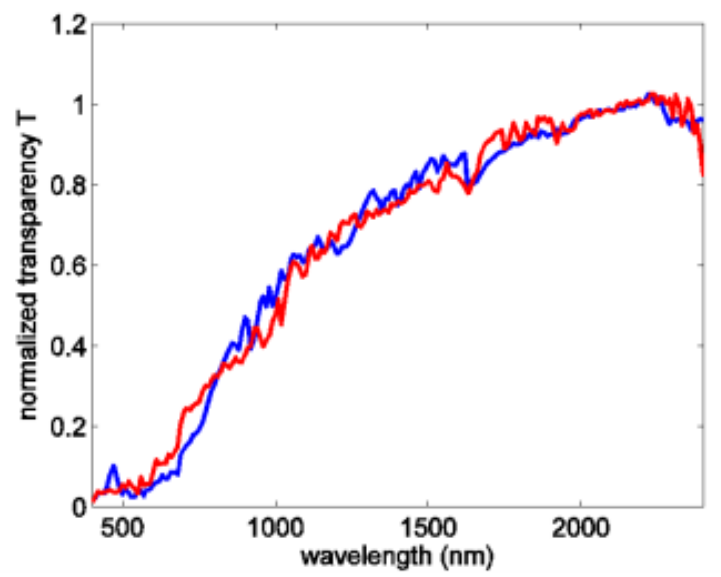

Fig. 6 Median normalized spectral transparency (normalized at 2200nm) for pigments in use before the nineteenth century (pigments in italic fonts in table 1) but excluding the lake pigments. Those in an oil medium are shown in blue and those in egg tempera are shown in red.

Figure 7a shows that the transparency of an un-pigmented egg tempera film decreases with decreasing wavelength in the range of $400-1900 \mathrm{~nm}$, whereas the transparency of unpigmented linseed oil stays constant between $600-2200 \mathrm{~nm}$. This is consistent with the $930 \mathrm{~nm}$ OCT images, in which egg tempera appears moderately scattering (Fig. 7c), but linseed oil is transparent (Fig. 7b). The reduced transparency of egg tempera at shorter wavelength is at least partially due to scattering. Paints in egg tempera are significantly less transparent compared to oil paints. This is partly due to the difference in refractive indices of egg tempera $(\mathrm{n}=1.346)$ and linseed oil $(\mathrm{n}=1.478)$ [24]. Pigments tend to have larger refractive indices than either medium. High scattering properties of paint are due to a large difference between the refractive index of the pigment and the binding medium. In addition, egg tempera is less homogeneous compared with linseed oil and hence more scattering. However, the difference in optical properties between the two binding media does not change the overall trend in spectral dependence of transparency for the paint samples (Fig. 6). This also suggests that the paint transparency is dominated by the properties of the pigments rather than the binding media.

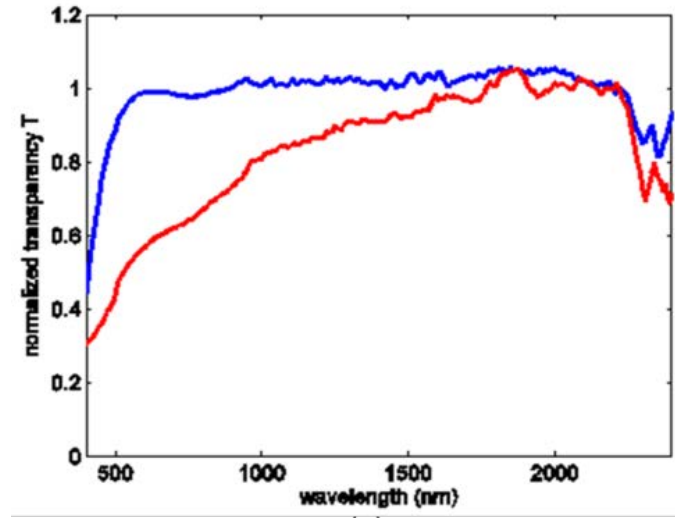

(a)

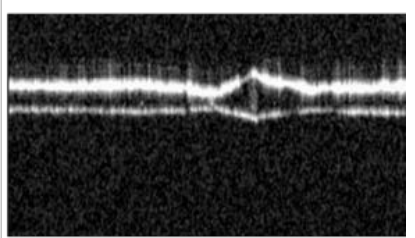

(b)

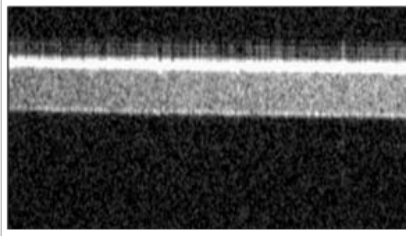

(c)

Fig. 7 a) Spectral transparency of the binding media normalized at 2200nm (linseed oil is in blue and egg tempera is in red). OCT (930nm) images of b) unpigmented linseed oil and c) unpigmented egg tempera films on glass. 
Having established the spectral dependence of transparency for the reference samples of paint containing different pigments, it is important to explore whether this trend is influenced by other factors such as the pigment to medium ratio and particle size since these are likely to vary depending on the artist's practice, as well as the grade and manufacturing process of the pigment powder.

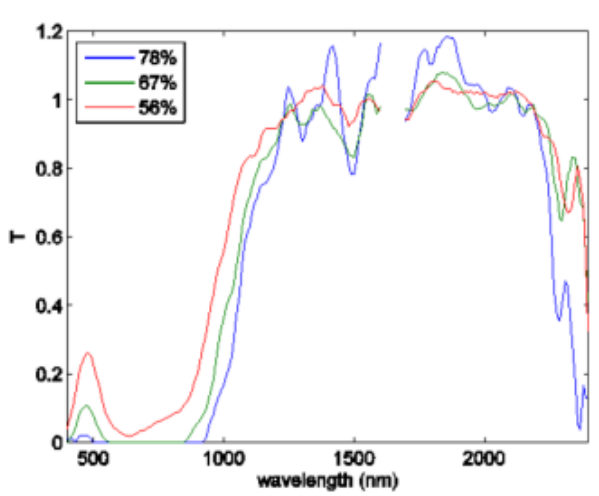

(a)

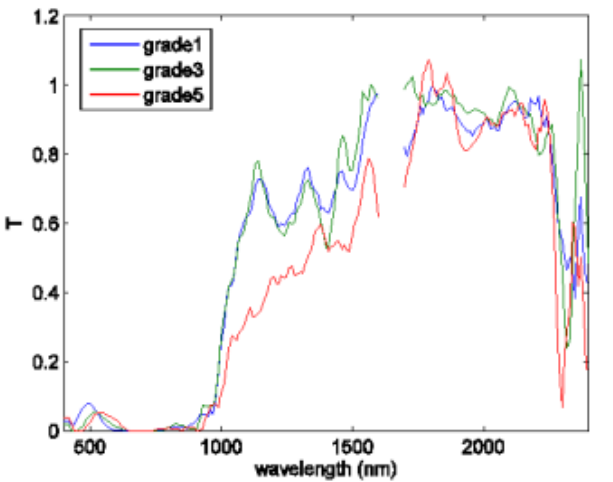

(b)

Fig.8 Normalized transparency (normalized to 1 at 2200nm) of azurite in egg tempera a) at mass concentration of $78 \%, 67 \%$ and $56 \%$; b) at average particle sizes of $\sim 30 \mu \mathrm{m}$ (grade 1), $\sim 5 \mu \mathrm{m}$ (grade 3) and $\sim 3 \mu \mathrm{m}$ (grade 5). The gaps around $1700 \mathrm{~nm}$ correspond to low detector sensitivity at the edge between DTS1700 and DTS2500 spectrometers.

Figure 8a shows that the wavelength dependence of transparency does not change with concentration over the range of mass concentrations studied. However, Fig. 8b shows that for the smallest particle size paint (Grade 5), there is even greater advantage in using a longer wavelength than the larger particle sizes (Grade 1 and 3). The shift of up to $27 \mathrm{~nm}$ at the peak around 460nm (Fig. 8b) is due to a similar shift in spectral reflectance as particle size changes [26]. Similarly, there is a shift of up to $12 \mathrm{~nm}$ towards the longer wavelengths at the $\sim 460 \mathrm{~nm}$ peak in the spectral reflectance of azurite as concentration increases [26]. These shifts in spectral features due to difference in concentration and particle sizes have to be taken into account when comparing unknown reflectance spectra with reference spectra for pigment identification (see section 5.3). While Fig. 8 shows a specific example of azurite in egg tempera, other pigments tested also showed similar trends.

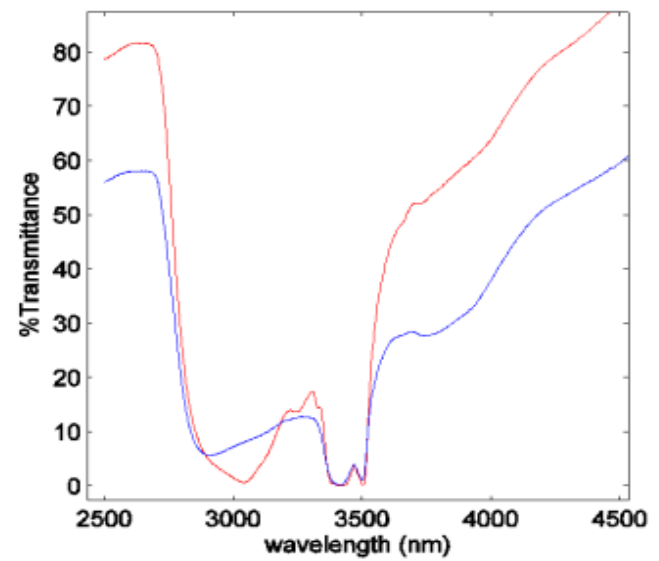

Fig. 9 Spectral transmittance of linseed oil (blue) and egg tempera (red) measured with FTIR between 2500$4500 \mathrm{~nm}$. The layer thicknesses are not equal in the two cases. 
Transparency of paint at wavelength greater than $2.5 \mu \mathrm{m}$ was investigated by measuring the spectral transmittance of thin films of binding media (linseed oil and egg tempera) on glass microscope slides using a PerkinElmer Spectrum 100 FTIR spectrometer. Glass transmits up to wavelength of $\sim 4.5 \mu \mathrm{m}$. A blank microscope slide was used as the reference to obtain the spectral transmittance of the two binding media shown in Fig. 9. Both linseed oil and egg tempera have broad and strong absorption features in the wavelength range 2.65-4.2 $\mu \mathrm{m}$ due to vibration modes of the $\mathrm{C}-\mathrm{H}$ and $\mathrm{O}-\mathrm{H}$ bonds. It was also noticed in Fig. 8a that these binding media have absorption features between $2.25-2.4 \mu \mathrm{m}$. Therefore it can be concluded that even over the wavelength range of $0.4-4.5 \mu \mathrm{m}$, egg tempera and linseed oil based paint layers are still likely to be most transparent around $2.2 \mu \mathrm{m}$.

\section{Discussions}

\subsection{Optimum spectral window for maximum depth penetration}

Measurements in the above section demonstrate that the optimum spectral window for maximum depth of penetration is around $2.2 \mu \mathrm{m}$ for the VIS/NIR spectral range $(0.4-4.5 \mu \mathrm{m})$. Factors such as binding medium, particle size and concentration do not change this conclusion. Unlike biological tissues, water absorption is not the main limiting factor for historic artists' paint. At wavelength shorter than $2.2 \mu \mathrm{m}$, scattering coefficients of most pigments increase with decreasing wavelength; at wavelength longer than $2.25 \mu \mathrm{m}$, absorption by egg tempera and linseed oil binding media reduces the transparency. The optimum spectral window for an OCT designed for imaging paint layers would thus be around 2.0-2.2 $\mu \mathrm{m}$. Since the depth resolution of OCT is given by $\Delta z=0.44 \lambda_{0}^{2} / \Delta \lambda$, an OCT with a source central wavelength $\lambda_{o} \sim 2 \mu \mathrm{m}$ would need to have a FWHM bandwidth of $\Delta \lambda \sim 180 \mu \mathrm{m}$ to achieve a theoretical depth resolution of $10 \mu \mathrm{m}$. Therefore a broadband source in the spectral window of 1.8-2.2 $\mu \mathrm{m}$ would be suitable. However, one of the challenges of building OCTs in this spectral window is the lack of readily available ultra-broadband sources. To achieve the same depth resolution, an OCT at a longer wavelength needs to have a much broader band since the depth resolution scales as central wavelength squared.

Currently, off-the-shelf OCT sources are commonly found around $800 \mathrm{~nm}, 1000 \mathrm{~nm}$, $1300 \mathrm{~nm}$ and $1500 \mathrm{~nm}$. Excluding the lake pigments (which are all highly transparent at wavelength $>600 \mathrm{~nm}$ ), over $30 \%$ of the paint samples are $>5$ times more transparent at $2.2 \mu \mathrm{m}$ than at $800 \mathrm{~nm}$, and $\sim 25 \%$ of the paint samples are $>2$ times more transparent at $2.2 \mu \mathrm{m}$ than at $1.5 \mu \mathrm{m}$. Apart from the general trend of increasing transparency with wavelength, there are also specific absorption features that make some of these off-the-shelf sources less than ideal. Around $800 \mathrm{~nm}$, the copper-based pigments azurite, malachite and verdigris have minimum transparency corresponding to absorption troughs between $700-1000 \mu \mathrm{m}$; around $1500 \mathrm{~nm}$, Cobalt pigments have minimum transparency corresponding to the broad absorption trough at 1300-1600nm.

Dispersion effects due to the wavelength dependence of the refractive index of a material can degrade the imaging resolution. However, paint and varnish layers are rarely over $500 \mu \mathrm{m}$ thick and therefore dispersion will not have an appreciable effect on the depth resolution.

\subsection{Optimum spectral window for imaging of underdrawings}

Infrared imaging of paintings is routinely used to obtain images of preparatory sketches (underdrawings) beneath the paint layers. OCT has been found to be particularly effective at 
high resolution and high contrast imaging of underdrawings owing to the advantages of interferometry [5][10]. Figure 10 shows an example where OCT has given images of underdrawing at a higher resolution and greater contrast than those obtained with an InGaAs near infrared camera [25].

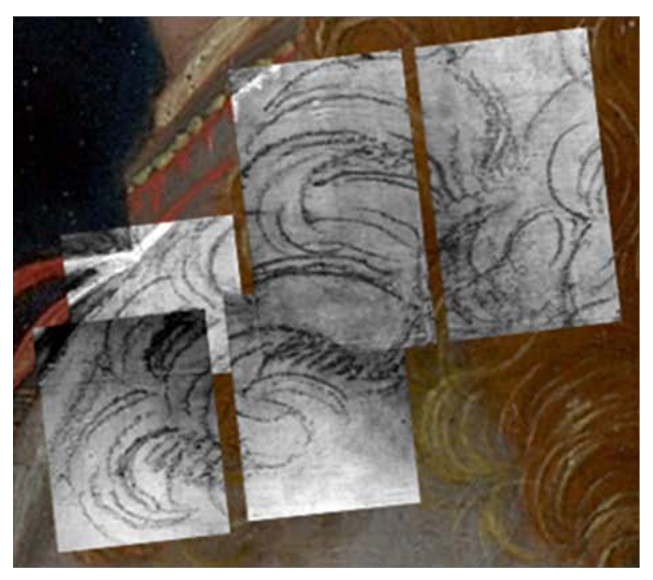

(a)

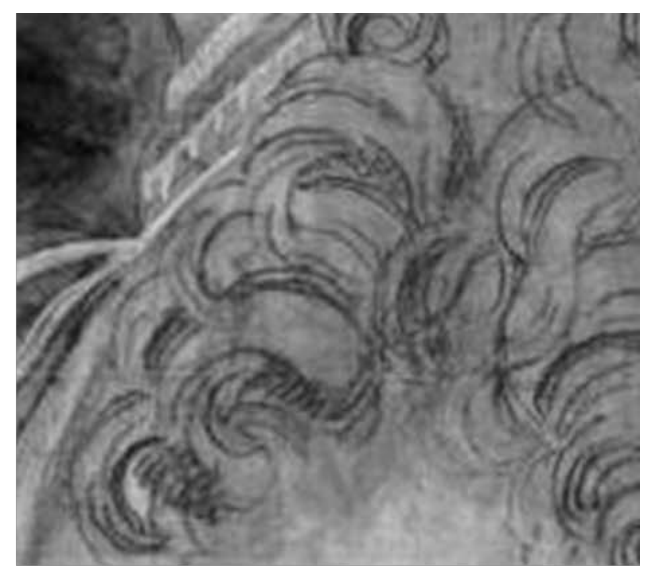

(b)

Fig. 10. After Francesco Francia, The Virgin and Child with an Angel (NG 3927) (C) National Gallery London: a) 930nm OCT images averaged over the depth region with clear underdrawings overlaid on a colour image of parts of the painting; b) NIR image with the SIRIS camera based on an InGaAs detector (900-1700nm).

Figure 11 gives an example of a painting where the OCT image at 930nm shows limited ability to reveal an underdrawing line where the near infrared image (InGaAs detector 900$1700 \mathrm{~nm})$ shows it clearly. The paint layer in this case contains azurite which is 4 times more opaque at $930 \mathrm{~nm}$ than at $1500 \mathrm{~nm}$. The underdrawing can only be detected by the OCT in regions where the azurite paint layer is thin or where the proportion of azurite in the paint layers above is low, such as in the shadowed area of the drapery at the top right corner of Fig.11a. Although no paint sample was taken from the exact area imaged with OCT, judging by the microscope images of the paint samples from other areas of the drapery (e.g. Fig. 1b, from a half shadow), the paint in the shadows is a mixture of azurite and red lake, with a high proportion of red lake in the darkest areas. As shown in Fig. 5e, lake paints are highly transparent at $930 \mathrm{~nm}$. A high proportion of red lake and low proportion of azurite results in paint layers of higher transparency. In the area of the OCT image where the underdrawing line is visible, it is of much higher resolution than in the conventional infrared image and shows clearly the detailed features of the drawing (Fig. 11a). Since the drawing can be seen in the conventional NIR image that is sensitive at wavelength $>900 \mathrm{~nm}$, it would be of great benefit to examine this painting using a longer wavelength OCT.

For the best visibility of the underdrawing, it is necessary to have not only high transparency of the paint layers on top, but also high contrast between the drawings and the substrate on which they have been made. For this study, a set of references of common underdrawing materials were prepared: two types of metal point (lead-tin alloy and silver), iron gall ink, lamp black watercolour paint, and the dry drawing materials charcoal, black chalk, red chalk and a red Conté pastel crayon were used to draw or paint lines on a white commercially prepared panel. 
Spectral reflectance was measured for each type of underdrawing and the white background. Figure 12 shows the normalized contrast of the underdrawings as a function of wavelength. The contrast is defined as $\zeta=\left(R_{b g}-R_{u d}\right) / R_{b g}$, where $R_{u d}$ and $R_{b g}$ are the spectral reflectance of the underdrawing and the white background respectively. The contrast of the two red drawing materials, coloured by iron oxide, drops sharply between $500 \mathrm{~nm}$ and $700 \mathrm{~nm}$; and the contrast of iron gall ink drops steadily until $1000 \mathrm{~nm}$ when it reaches a plateau. These underdrawing materials are known to be difficult to detect in the near infrared as they are relatively transparent in this region. Since the red chalk and crayon are essentially transparent beyond $700 \mathrm{~nm}$ and most paint is opaque at wavelengths less than $700 \mathrm{~nm}$, there is little chance of detecting underdrawings made with these materials unless the paint layers above are very thin. The best chance of detecting iron gall ink underdrawings is in the very near infrared between 700 and 900nm. Apart from black chalk, all the underdrawing materials studied have fairly constant contrast between $1 \mu \mathrm{m}$ and $2.4 \mu \mathrm{m}$. Therefore for the detection of underdrawings, on the whole it is still best to image at the spectral window where paints are most transparent, i.e. around $2.2 \mu \mathrm{m}$. The exceptions are iron gall and black chalk where depending on the paint, for example smalt, lapis lazuli or lead white, there may be a better chance of seeing these underdrawings in the 700-1000nm range (compare Fig. 5 and 12).

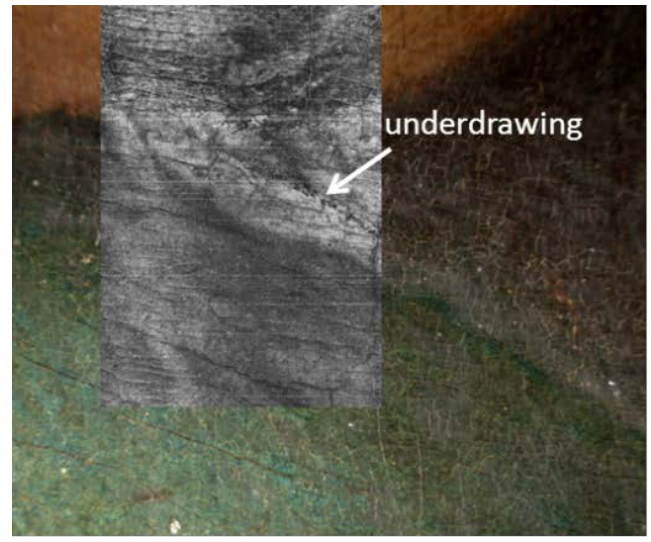

(a)

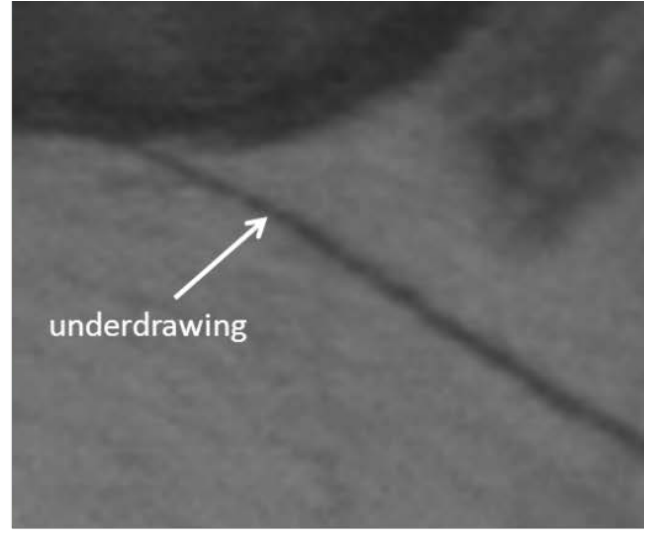

(b)

Fig. 11 After Raphael, The Madonna and Child (NG929), probably before 1600 (C) National Gallery London: a) a 930nm OCT en face image medianed over the paint layers (optical depth range $\sim 250 \mu \mathrm{m}$ ) overlaid on a colour image of the painting in region A of Fig. 1); b) Infrared image of the same region as in a) (broad band from 900 to $1700 \mathrm{~nm}$ ). 


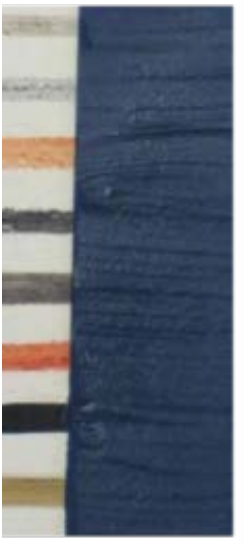

(a)

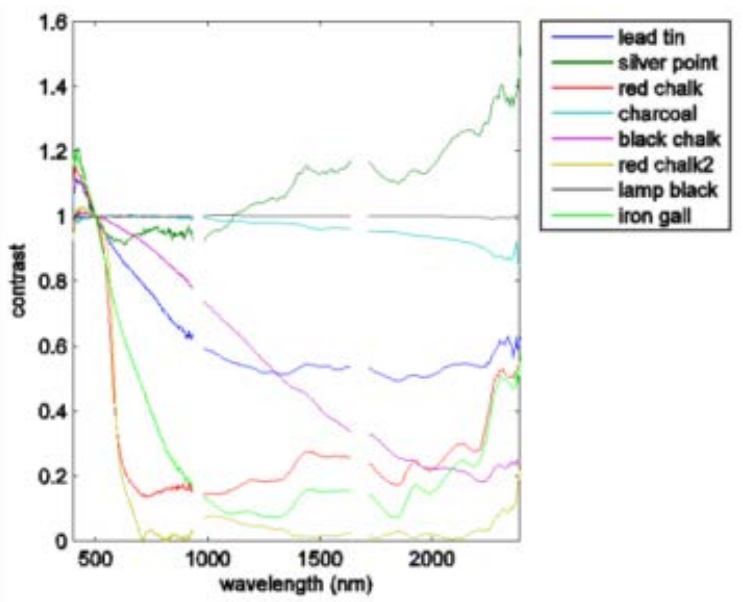

(b)

Fig. 12 a) Underdrawing panel with horizontal lines of drawing material from top to bottom: lead-tin alloy, silver point, red chalk, charcoal, black chalk, red Conté pastel, lamp black and iron gall partially covered with a stripe of azurite oil paint; b) Contrast spectrum of the underdrawing materials (bare underdrawing away from the painted region) against the white background normalized to 1 at $500 \mathrm{~nm}$. The broad feature around $1500 \mathrm{~nm}$ and the feature around $1900 \mathrm{~nm}$ are due to the absorption features associated with the gesso preparation layer. The gaps correspond to the edges of the spectrometers' sensitivity ranges.

\subsection{A reference spectral library of historic artists’ paints}

One of the by-products of this study is spectral reflectance data from a chemically verified set of common historic artists' paints in the visible and near infrared (400-2400nm) measured over a white and black background. These can be used as a reference spectral library for noninvasive pigment identification using spectral reflectance measurements from either spectrometers or multispectral/hyperspectral imaging systems (e.g. [26] and references therein).

There is currently an online spectral reflectance library 'Fibre Optics Reflectance Spectra (FORS) of Pictorial Materials in the 270-1700 nm range' (http://fors.ifac.cnr.it/info.php) of historically accurate reproductions of common artists' paints on a gypsum ground layer [27]. While it is useful to have samples prepared in a historically accurate manner, the absorption features due to the gypsum ground layer mask any spectral features of the pigments in the $1450-1550 \mathrm{~nm}$ range.

The advantages of the current study are: i) the materials used to prepare the paints have been analysed at least with EDX (selected ones with FTIR, XRD and Raman) to confirm their chemical composition, ii) the paints have been applied on glass substrates which have no spectral features in the $400-2700 \mathrm{~nm}$ range, iii) the measurements over the spectral range 400-2400nm complement the existing online library and iv) the measurements over a white

and black background enable the scattering and absorption coefficients as a function of wavelength to be determined, e.g. using the Kubelka-Munk model for those cases that satisfy the assumptions of the model [28][29]. 


\section{Conclusions}

A comprehensive study of the spectral transparency of 45 chemically characterized historic artists’ pigments in oil and egg tempera showed that most pigments have significantly increased transparency at longer wavelength and all pigments have close to maximum transparency around $\sim 2200 \mathrm{~nm}$ over the spectral range of $400-2400 \mathrm{~nm}$. This is likely to be true even for an extended spectral range of 400-4500nm based on the absorption characteristics of the oil and egg tempera binding medium. This conclusion is consistent with earlier studies based on oil paints made with a few common pigments. OCT specifically built for the examination of paintings and painted objects should use the optimum spectral window around $2 \mu \mathrm{m}$ for maximum penetration depth. The same spectral window is optimum for OCT or conventional near infrared imaging of underdrawings. Development of wide-band light sources at this wavelength for OCT is desirable for imaging of paint and potentially any material without significant water content. A swept source OCT at $2 \mu \mathrm{m}$ is currently being developed for this purpose.

The spectral reflectance data form a useful reference library which complements existing online spectral libraries. In addition, the spectral measurements can be used to deduce the scattering and absorption properties of the samples over a wide spectral range.

\section{Acknowledgements}

Funding by the Royal Society, the Leverhulme Trust, EPSRC CASE award, AHRC/EPSRC Science \& Heritage Programme and Nottingham Trent University is gratefully acknowledged. We would like to acknowledge Sophie Martin-Simpson of Nottingham Trent University and Rachel Morrison of the National Gallery for preparing some of the historic artists' paint samples, Gareth Cave of Nottingham Trent University for the XRD confirmation of realgar and orpiment, Rachel Billinge of the National Gallery for allowing us to use the detail of the infrared reflectogram made with the SIRIS and OSIRIS cameras in Fig. 10b and Fig. 11b, and Sammy Cheung of Nottingham Trent University for taking the images in Fig. 2a,b.

\section{References}

1. W. Drexler, J. G. Fujimoto: Optical Coherence Tomography: Technology and Applications (Springer 2008)

2. M. Wojtkowski: Applied Optics, 49(16), D30 (2010)

3. D. Stifter: Appl. Phys. B 88, 337 (2007)

4. P. Targowski, B. Rouba, M. Wojtkowski, A. Kowalczyk: Studies in Conservation 49, 107 (2004)

5. H. Liang, M. Cid, R. Cucu, G. Dobre, A. Podoleanu, J. Pedro, D. Saunders: Opt. Express 13, 6133 (2005)

6. T. Arecchi, M. Bellini, C. Corsi, R. Fontana, M. Materazzi, L. Pezzati, A. Tortora: Opt. Spectrosc. 101, 23 (2006)

7. D. C. Adler, J. Stenger, I. Gorczynska, H. Lie, T. Hensick, R. Spronk, S. Wolohojian, N. Khandekar, J. Y. Jiang, and S. Barry: Optics Express 15, 15972 (2007)

8. M. Spring, H. Liang, B. Peric, D. Saunders, A. Podoleanu: in International Council of Museums (ICOM) Committee for Conservation Triennial Conference, Preprints Vol. II (Allied Publishers, New Delhi, 2008), p.916

9. $\quad$ Lawman S., Liang H.,:Applied Optics 50(32), 6039 (2011)

10. H. Liang, B. Peric, M. Hughes, A.G. Podoleanu, M. Spring, and S. Roehrs: Proc. SPIE 7139, 713915 (2008)

11. P. Targowski, M. Iwanicka: Applied Physics A, 106(2), 265 (2011)

12. Y. Wang, J. S. Nelson, Z. Chen, B. J. Reiser, R. S. Chuck, R. Windeler: Optics Express 11, 1411-1427 (2003)

13. A. Sainter, T. King, M. Dickinson: Journal of Biomedical Optics 9, 193 (2004) 
14. J. R. J. van Asperen de Boer: Applied Optics 7, 1711 (1968)

15. J. R. J. van Asperen de Boer: Studies in Conservation, 14, 96 (1969)

16. E. Walmsley, C. Fletcher, J. Delaney: Studies in Conservation 37, 120 (1992)

17. M. Gargano, N. Ludwig, G. Poldi: Infrared Physics \& Technology 49, 249-253 (2007)

18. A. Szkulmowska, M. Góra, M. Targowska, B. Rouba, D. Stifter, E. Breuer, and P. Targowski: in Lasers in the Conservation of Artworks, LACONA VI Proceedings, (Springer Verlag, BerlinHeidelberg-New York, 2007), p. 487

19. L. Carrion, M. Lestrade, Z. Xu, G. Touma, R. Maciejko, M. Bertrand: Journal of Biomedical Optics 12, 014017 (2007)

20. A. Alex, B. Povazay, B. Hofer, S. Popov, C. Glittenberg, S. Binder, W. Drexler: Journal of Biomedical Optics 15, 026025 (2010)

21. V. M. Kodach, J. Kalkman, D. J. Faber, T. G. Van Leeuwen: Biomedical Optics Express 1, 176 (2010)

22. J M Schmitt, A Knuttel, M Yadlowsky, M A Eckhaus: Phys. Med. Biol. 39, 1705 (1994)

23. Y. Pan, D. L. Farkas: Journal of Biomedical Optics 3(4), 446 (1998)

24. T. B. Brill, Light: Its Interaction with Art and Antiquities (New York: Plenum Press, 1980)

25. D. Saunders, R. Billinge, J. Cupitt, N. Atkinson and H. Liang: Studies in Conservation 51 (4), 277 (2006)

26. H. Liang: Applied Physics A 106 (2), 309 (2012)

27. M. Bacci, S. Baronti, A. Casini, F. Lotti, M. Picollo, O. Casazza: Materials Research Society Symposium Proceedings 267, 265 (1992)

28. P. Kubelka: J. Opt. Soc. Am. 38, 448 (1948)

29. W. E. Vargas, G. Niklasson: Applied Optics 36 (22), 5580 (1997) 